Article

\title{
Bioactive and Antibacterial Coatings Based on Zein/Bioactive Glass Composites by Electrophoretic Deposition
}

\author{
Nima Meyer ${ }^{1,+}$, Laura Ramos Rivera $^{1,+}{ }^{+}$Tim Ellis $^{2}$, Jiahui Qi ${ }^{2}{ }^{(D)}$, Mary P. Ryan ${ }^{2}$ and \\ Aldo R. Boccaccini ${ }^{1,2, *}$ \\ 1 Institute of Biomaterials, Department of Materials Science and Engineering, University of \\ Erlangen-Nuremberg, 91058 Erlangen, Germany; nimameyer@yahoo.de (N.M.); laura.ramos@fau.de (L.R.R.) \\ 2 Department of Materials, Imperial College London, London SW7 2AZ, UK; t.ellis14@imperial.ac.uk (T.E.); \\ j.qi@imperial.ac.uk (J.Q.); m.p.ryan@imperial.ac.uk (M.P.R.) \\ * Correspondence: aldo.boccaccini@ww.uni-erlangen.de; Tel.: +49-9131-852-8601; Fax: +49-9131-852-8602 \\ + These authors contributed equally to this work.
}

Received: 10 August 2017; Accepted: 15 December 2017; Published: 8 January 2018

\begin{abstract}
This study investigated the electrophoretic deposition (EPD) of the natural polymer zein combined with bioactive glass (BG) particles. Through the deposition of various BG compositions, namely 45S5 BG and Cu-doped BG, this work sought to demonstrate the ability of the films to potentiate the formation of hydroxyapatite (HA) in contact with simulated body fluid (SBF). Following incubation in SBF, the physical and chemical surface properties of the EPD films were evaluated using different characterization techniques. The formation of HA at the surface of the coatings following immersion in SBF was confirmed using Fourier transform infrared spectroscopy (FTIR). The results demonstrated HA formation in all coatings after seven days of immersion in SBF. Coating morphology and degradation of the zein films were characterized using environmental scanning electron microscopy (ESEM). The results confirmed EPD as a very convenient room temperature technique for production of ion releasing, bioactive, and antibacterial coatings for potential application in orthopedics.
\end{abstract}

Keywords: electrophoretic deposition; composite coating; bioactive glass; zein; biomaterials

\section{Introduction}

The demand for bioactive metallic implants that promote biological adhesion to bone tissue continues to rise, driving the development of new bio-responsive surfaces for stainless steel and titanium alloy orthopedic prostheses [1-3]. Bioactive glass (BG) coatings exhibit significant osteoinductive (stimulation of bone cells) and osteoconductive (surface suitable for bone growth) properties, interacting with the surrounding tissue at a cellular level through the release of biologically active ions [4-7]. In order to mimic the composite structure of natural bone, biodegradable polymer/BG composite coatings are increasingly being investigated for orthopedic purposes [8]. This approach not only combines the ideal bulk mechanical properties of the metallic implants (i.e., tensile strength and toughness) with the desired surface properties offered by BG, but it also eliminates the need for high temperature processing required for pure BG coatings. The use of high temperatures is not desired because they can lead to BG crystallization and microstructural changes resulting in possible substrate damage. Moreover, resorbable biopolymers acting as BG support coatings can accelerate the bonding process between new tissue and the surface of metallic implants by exploiting the polymer gradual degradation. This caters for the growth of new tissue into the implant interface [9]. In addition, the level of ion release from BG particles can be controlled by the degradable biopolymer matrix, 
which can also act as a vehicle for conventional drug release facilitating bone growth [10]. Therefore, inorganic/organic composite coatings offer great potential, enabling surface functionalization, chemical bioactivity, and drug delivery capacity for different purposes, e.g., antibacterial effect, growth factor release, or even analgesic functions [8,10-12].

Due to their biocompatibility and biodegradability, natural polymers have gained huge interest for biomedical application [13]. Zein is one of the natural polymers that has found its way into medical and pharmaceutical applications due to its attractive features of being biodegradable, bioadhesive, and potentially antibacterial $[14,15]$. The protein zein belongs to the alcohol soluble protein class known as prolamine proteins that are separated from maize endosperm [16]. Zein can be classified in four distinct fractions; namely, $\alpha-, \beta-, \gamma-$, and $\delta$-zein $[17,18]$. The structure of zein is composed of homologous $\alpha$-helices [19], containing high levels of hydrophobic amino acids such as leucine, proline, and alanine that account for more than half of the protein [20]. Zein also contains high levels of hydrophilic residues, such as glutamine, that gives rise to its zwitterionic nature. The structure of $\alpha$-zein is composed of homologous repeat units, which comprise a helical wheel ( $\alpha$-helix) conformation. This three-dimensional network as seen in Figure 1 is aligned in two different arrangements; cylindrical and ribbon-like models, where the hydrophobic helices are ranked edgewise while the hydrophilic glutamine bridges link the upper and lower surfaces of the repeat units.

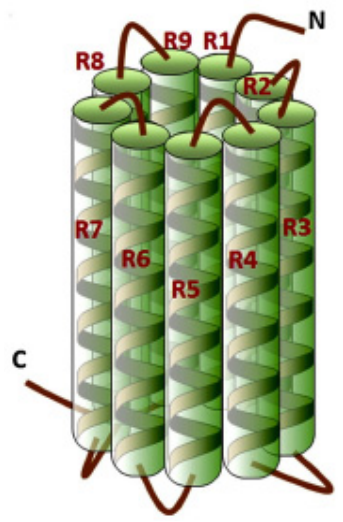

(a)

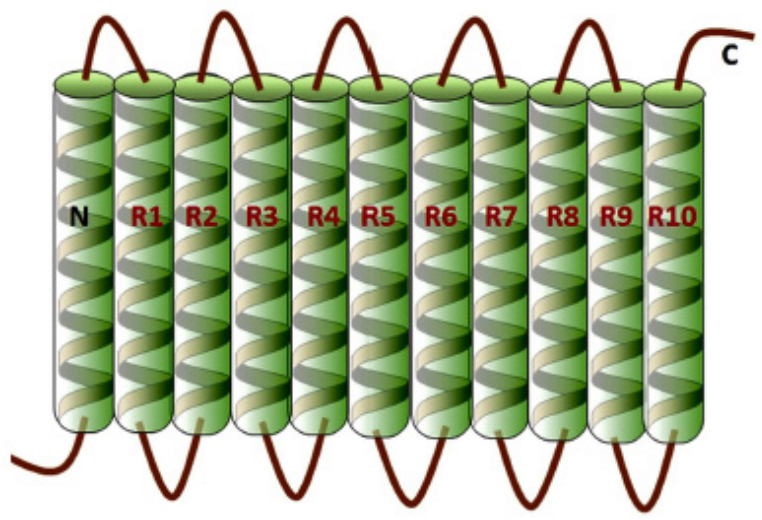

(b)

Figure 1. Two proposed three-dimensional structures of $\alpha$-zein: (a) cylindrical model; (b) ribbon-like model [20]. (Reproduced from [20] with permission; Copyright 2015 Elsevier.)

These biochemical properties make this natural polymer an interesting candidate for a variety of deposition techniques that can be translated to surface functionalization of metal implants. Zein has been also combined with inorganic phases to form composites for several biomedical applications [21].

Different techniques, such as aerosol deposition [9], dip coating [22], and layer by layer (LBL) deposition [23,24] have been used to fabricate inorganic/organic composite coatings on metallic substrates. Electrophoretic deposition (EPD) has recently gained attention as a simple and economic manufacturing process, offering the ability to fabricate uniform coatings on complex-shaped substrates at room temperature $[4,8,12,25,26]$. During EPD, charged particles or molecules in suspension migrate to the oppositely charged electrode (substrate) where they are then deposited. There is very limited previous work reporting the EPD of zein [27-29], and there has been no previous investigation with regards to EPD of a zein/BG composite. This work presents for the first time the fabrication of zein/BG composite coatings formed through EPD. By utilizing a range of characterization techniques, this investigation seeks to evaluate zein/BG composites considering both copper-doped and non-doped bioactive glasses for orthopedic applications. 


\section{Experimental Procedure}

\subsection{Materials}

BG powder of $45 \mathrm{~S} 5$ composition ( 45.0 wt. $\% \mathrm{SiO}_{2}, 24.5$ wt. $\% \mathrm{Na}_{2} \mathrm{O}, 6.0$ wt. $\% \mathrm{P}_{2} \mathrm{O}_{5}, 24.5$ wt. $\% \mathrm{CaO}$ ) with particle size in range of 5.0-25.0 $\mu \mathrm{m}$ and $45 \mathrm{~S} 5 \mathrm{BG}$ doped with $2.5 \mathrm{wt} . \% \mathrm{CuO}$ [30] with an average particle size of $5.0 \mu \mathrm{m}$ were used. Zein powder (Z3625-500 g) was purchased from Sigma-Aldrich (St. Louis, MO, USA). Commercial stainless steel AISI 316L (ThyssenKrupp AG, Essen, Germany) plates of $0.2 \mathrm{~mm}$ thickness were used as substrates (both as deposition and counter electrodes). Glycerol (Sigma-Aldrich) and ethanol (Merk KGaA, Darmstadt, Germany) with 99\% purity were used for EPD.

\subsection{EPD of Zein/45S5 BG Composite Coatings}

A mixture of ethanol (90 vol.\%) and water (10 vol.\%) with added glycerol (3 vol.\%) was used to solubilize zein powder (15 wt.\%) whilst stirring. BG particles $(8 \mathrm{wt} . \%)$ were added to the solution, and the final suspensions were sonicated for $30 \mathrm{~min}$ prior to EPD. The substrates were prepared by cutting stainless steel plates of dimensions: $15 \mathrm{~mm}$ width and $30 \mathrm{~mm}$ length, which were cleaned in successive ultrasonic baths of acetone, ethanol, and water for 10 min each. The distance between the electrodes in the EPD cell (deposition and counter electrode) was fixed $(10 \mathrm{~mm})$ for the entire experiment. The deposition area was kept constant at $20 \times 15 \mathrm{~mm}^{2}$.

In order to control the coating thickness and to reduce the formation of surface cracks, both deposition time (in the range of $0.5-10 \mathrm{~min}$ ) and voltage (in the range of 3-10 V) were varied. During the EPD process, the suspension was stirred and sonicated for each sample. The optimized coating conditions for each zein/BG film are shown in Table 1. Following EPD, samples were air dried for at least $24 \mathrm{~h}$ before film characterization was conducted.

Table 1. Produced coatings showing optimized EPD conditions. BG = bioactive glass.

\begin{tabular}{ccc}
\hline \multicolumn{3}{c}{ Produced EPD Coatings } \\
\hline Deposited Coatings & Deposition Time & Voltage \\
\hline Zein/45S5 BG & $2 \mathrm{~min}$ & $10 \mathrm{~V}$ \\
Zein/45S5 BG Cu-doped & $5 \mathrm{~min}$ & $3 \mathrm{~V}$ \\
\hline
\end{tabular}

The in vitro investigation to assess bioactivity, characterized by the formation of hydroxyapatite, was carried out by immersing the EPD films in simulated body fluid (SBF). Both the preparation of SBF and the amount of SBF used per experiment were obtained following Kokubo's protocol [31]. Each film was soaked in $40 \mathrm{~mL}$ of SBF for predetermined immersion times of 1, 3, 7, and 14 days at $37^{\circ} \mathrm{C}$. At each time point, coatings were removed and sequentially washed with deionized water and acetone to arrest the reaction before being left to dry at room temperature for at least $24 \mathrm{~h}$.

\subsection{Coating Characterization}

\subsubsection{Scanning Electron Microscopy}

The characterization of the coating's surface morphology was carried out by scanning electron microscopy (SEM) (IntouchScope/JSM 6010, JEOL Inc., Peabody, MA, USA). Samples were first plasma cleaned under nitrogen and oxygen for $30 \mathrm{~s}$ before the sample was sputtered with gold $(30 \mathrm{~s}, 20 \mathrm{~mA})$.

\subsubsection{Environmental Scanning Electron Microscopy}

Characterization of the coating surface microstructure was carried out using the Quanta 650 (FEI, Hillsboro, OR, USA) environmental SEM (ESEM), which enables the user to image under humidified and/or low vacuum conditions, avoiding or reducing the formation of surface cracks. 


\subsubsection{Energy Dispersive Spectroscopy (EDS)}

Energy dispersive $X$-ray spectroscopy was performed to analyze the chemical distribution of the ESEM images using the detector XFlash $6 \mid 60$ part of Quanta 650 (FEI).

\subsubsection{Thermogravimetric Analysis (TGA)}

TGA was carried out in order to determine the relative fraction of organic and inorganic components of the coatings using STA 449 C Jupiter (Netzsch-Gerätebau GmbH, Selb, Germany). The coatings were heated from room temperature to $800^{\circ} \mathrm{C}$ with a fixed heating rate of $10{ }^{\circ} \mathrm{C} / \mathrm{min}$ in an atmosphere of air.

\subsubsection{Zeta (ל)-Potential Measurements}

$\zeta$-potential measurements were carried out using Laser Doppler electrophoresis with a Zetasizer Nano ZS Malvern Instruments (Malvern, UK) equipment.

\subsubsection{Fourier Transform Infrared Spectroscopy (FTIR)}

In order to evaluate the chemical composition of the EPD films, FTIR was utilized using a Nicolet iS 10 instrument (Thermo Fisher Scientific Inc., Waltham, MA, USA) in transmission mode.

\subsubsection{X-ray Diffraction (XRD)}

$\mathrm{XRD}$ was applied to determine the formation of hydroxyapatite on the surface of coatings following immersion in SBF, using a D2 PHASER device (Bruker, Coventry, UK). XRD measurements were performed with a step size of $0.03^{\circ}$ for the $2 \theta$ range of $4^{\circ}-80^{\circ}$.

\section{Results and Discussion}

\subsection{Suspension Stability}

The colloidal stability of the zein/BG suspensions was investigated by measuring the zeta-potential. The $\zeta$-potential value in zein suspensions containing $45 \mathrm{~S} 5 \mathrm{BG}$ particles was $-13.0 \pm 1.0 \mathrm{mV}$ at $\mathrm{pH}$ of 9.2; and for copper-doped $45 \mathrm{~S} 5 \mathrm{BG}$, it was $-8.5 \pm 0.5 \mathrm{mV}$ at $\mathrm{pH}$ of 8.9. Negative zeta-potential values indicate an anodic deposition, i.e., negatively charged particles or molecules deposit on the positively charged electrode. The measured relatively low values of zeta-potential indicate a relatively low stability of the suspensions. The $45 \mathrm{~S} 5 \mathrm{BG}$ particles have a more negative zeta potential in suspension compared to the suspension containing Cu-doped $45 \mathrm{~S} 5 \mathrm{BG}$. However, both systems contain relatively large particles which may sediment due to gravity and this will also affect the deposition [26].

\subsection{Deposition Mechanism}

The $\zeta$-potential values of both suspensions suggest that the particles would deposit anodically, however, composite coatings were produced on the cathode. This phenomenon is possibly related to the complexity of zein and its behavior in aqueous solution depending on the various functional groups of amino acids, such as amides, amines, hydroxyls, carboxyls, and phenols. However, hydroxyls, carboxyls, and phenols occur mostly as deprotonated groups and are negatively charged, whereas the protonated amines and amides are responsible for the positively charged ions of the amino acid. Zein molecules containing both groups are likely to associate with BG particles in suspension forming BG/polymer composite entities.

We hypothesize that during EPD, as the electric field is applied, the hydrophilic parts of zein molecules bond with the bioactive glass particles and then migrate together to the negative electrode. It is possible also that zein molecules migrate to the anode due to their negative charge. Thus, both anodic and cathodic depositions could in theory occur simultaneously depending on the state of the secondary protein structure [32] which will dominate the deposition process in weakly charged systems. 
The cathodic deposition of zein is assumed to be similar to that of chitosan $[27,33]$ and it may take place as described next. The protonation of amine groups of zein occurs in the presence of hydronium ions and, according to reaction (1), it results in ammonium ions and water:

$$
\left[\text { Zein }-\mathrm{NH}_{2}\right]+\mathrm{H}_{3} \mathrm{O}^{+} \rightarrow\left[\text { Zein }-\mathrm{NH}_{3}^{+}\right]+\mathrm{H}_{2} \mathrm{O}
$$

Furthermore, as the EPD process continues, water in the suspension electrolyzes and the local $\mathrm{pH}$ at the cathode increases which causes alkaline conditions on the cathode surface as $\mathrm{OH}^{-}$ions are produced:

$$
2 \mathrm{H}_{2} \mathrm{O}+2 \mathrm{e}^{-} \rightarrow \mathrm{H}_{2}+2 \mathrm{OH}^{-}
$$

Hence, electrophoresis of ammonium ions of zein towards the cathode takes place, the protonated amine groups of zein (ammonium ions) lose their charge and build an insoluble deposit:

$$
\left[\text { Zein }-\mathrm{NH}_{3}^{+}\right]+\mathrm{OH}^{-} \rightarrow\left[\text { Zein }-\mathrm{NH}_{2}\right] \downarrow+\mathrm{H}_{2} \mathrm{O}
$$

The BG particle surface charge, which is due to surface-bound hydroxyl groups, depends on the suspension's $\mathrm{pH}$ [34]. Based on the $\mathrm{pH}$ of the suspension and considering the measured zeta-potential of BG particles, it was found that the surface charge of bioactive glass particles exhibits a negative value. This negative charge of the BG particles can bind with the positive charges of zein forming $\mathrm{BG} /$ zein composite particles and also leading to motion of the particles towards the cathode.

\subsection{Thermogravimetric Analysis}

TGA measurements were performed to assess the change in mass of the EPD films as a function of temperature, comparing the TGA behavior of the control (pure zein) coating with that of BG/zein composite coating. Figure 2 displays an initial reduction in mass of approximately $5 \%$ (shown in green) which is likely attributable to the loss of volatiles from the zein coating. The next reduction in mass $(\sim 5 \%)$ was observed between 180 and $220^{\circ} \mathrm{C}$ which is likely caused by evaporation of glycerol that has a boiling point of $198{ }^{\circ} \mathrm{C}$ [34]. The changes in mass at 230,480 , and $650{ }^{\circ} \mathrm{C}$, leading to a mass reduction of approximately $50 \%, 30 \%$, and $10 \%$ respectively, are the result of the degradation of the zein primary protein structure and subsequent combustion of the amino acids/peptides formed [35].

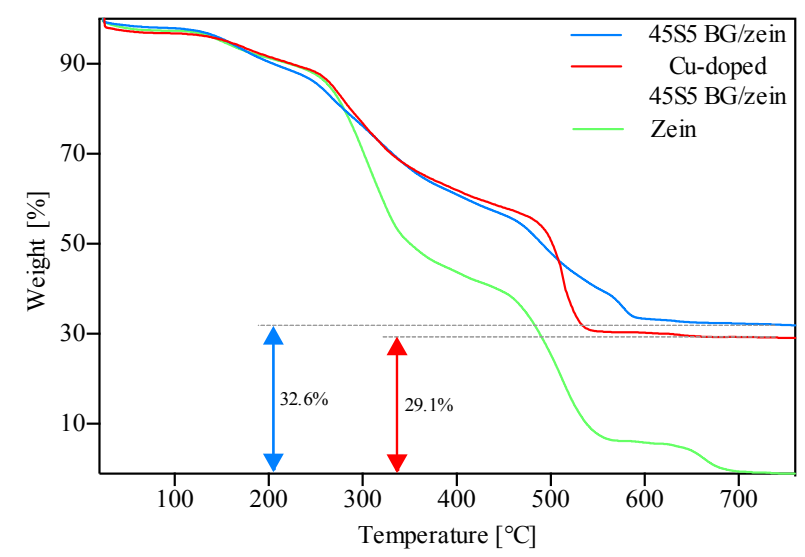

Figure 2. TGA results on coatings produced with $45 \mathrm{~S} 5 \mathrm{BG} /$ zein, Cu-doped $45 \mathrm{~S} 5 \mathrm{BG} / \mathrm{zein}$, and pure zein.

\subsection{Fourier Transform Infrared Spectroscopy}

In order to confirm the presence of zein and bioactive glass and to analyze the chemical characteristics of the films regarding their bioactivity, FTIR of the coatings was performed. Furthermore, 
the investigation was extended to coatings that had been immersed in SBF to analyze the coating's behavior in a relevant environment, i.e., to determine bioactivity following Kokubo's protocol [31].

Figure 3 confirms the presence of zein molecules in all coatings indicated by three characteristic vibrational bands, namely: amid I $\left(1650 \mathrm{~cm}^{-1}\right)$; amid II $\left(1510 \mathrm{~cm}^{-1}\right)$; and amid III $\left(1236 \mathrm{~cm}^{-1}\right)$, which correspond to $\mathrm{C}=\mathrm{O}$ stretching, $\mathrm{C}-\mathrm{N}$ stretching, and $\mathrm{N}-\mathrm{H}$ in plane deformation, respectively $[36,37]$. Further characteristic peaks of zein at $3340 \mathrm{~cm}^{-1}$ and $2930 \mathrm{~cm}^{-1}$ appear and are attributable to O-H stretching and $\mathrm{C}-\mathrm{H}$ stretching, respectively.

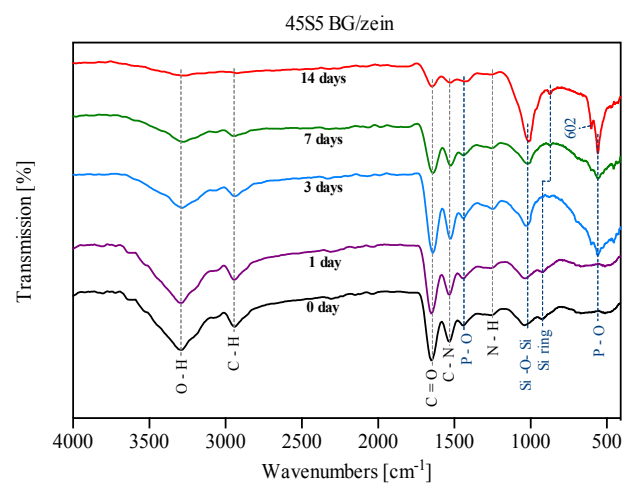

(a)

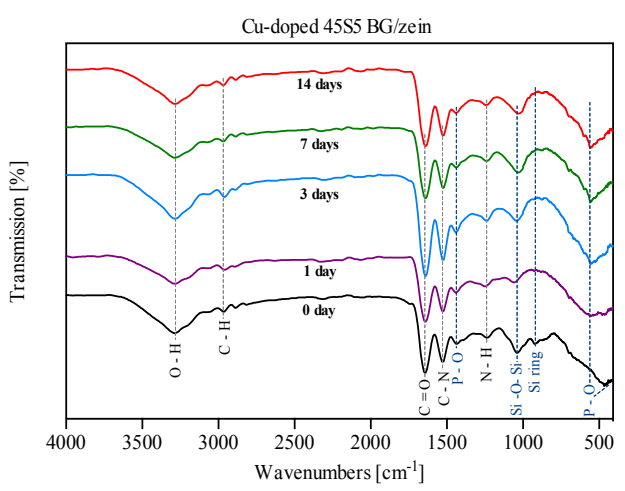

(b)

Figure 3. FTIR results on coatings before and after immersion in SBF for up to 14 days: (a) 45S5 BG/zein coatings; (b) copper-doped 45S5 BG/zein coatings. The main vibration bands of zein (blue dashed line) and BG (black dashed line) are depicted.

The transmission bands corresponding to the chemical functional groups of BG were also detected. The observed peak ascertained from the control coating that was not immersed in SBF (seen at $1043 \mathrm{~cm}^{-1}$ ) is attributed to the $\mathrm{Si}-\mathrm{O}-\mathrm{Si}$ asymmetric stretching [38]. In addition, the vibration mode of the silica ring structure was observed at $910 \mathrm{~cm}^{-1}$ [39]. The peaks at 1427, 500, and $650 \mathrm{~cm}^{-1}$ correspond to the stretching and bending vibrational mode of $\mathrm{P}-\mathrm{O}$ [39]. Furthermore, both coatings show, upon increasing time of immersion in SBF, more pronounced peaks at $560 \mathrm{~cm}^{-1}$ and $1043 \mathrm{~cm}^{-1}$. This is attributed to the bending vibration of $\mathrm{P}-\mathrm{O}$ and indicates formation of hydroxyapatite on the coating surface [40]. The dual peak at $560 \mathrm{~cm}^{-1}$ and $602 \mathrm{~cm}^{-1}$ that only appears on coatings with $45 \mathrm{~S} 5 \mathrm{BG}$ after 14 days of immersion in SBF indicates the formation of carbonated hydroxyapatite (P-O mode) [40].

The unchanged intensity of characteristic peaks of zein at $3340 \mathrm{~cm}^{-1}$ and $2930 \mathrm{~cm}^{-1}$ for Cu-doped $45 \mathrm{~S} 5 \mathrm{BG}$ suggests that during electrophoresis, $\mathrm{Cu}^{2+}$ ions are able to bind to carboxyl groups of amino acid side chains contained in zein and, therefore, the degradation of the polymer is reduced [41,42]. The protein break-down is not taking place as it was observed for $\mathrm{Cu}$-free BG containing coatings (this is also confirmed by the results of ESEM and XRD, as shown below).

\subsection{X-ray Diffraction Analysis}

The possible formation of hydroxyapatite (HA) on the coating, upon immersion in SBF, was investigated by XRD analysis. Figure 4 shows the XRD patterns of $45 S 5$ BG and Cu-doped $45 \mathrm{~S} 5 \mathrm{BG}$ coatings. As it can be noticed, there is a broad crystallization peak in all the coatings (1-14 days of soaking in SBF) at about $2 \theta=10^{\circ}$, corresponding to the semi-crystalline nature of zein [43]. Upon increasing immersion time in SBF, the peak related to crystallization of zein becomes slightly flattened, which is likely due to the degradation of the polymer with increased immersion time. Furthermore, the coatings based on Cu-doped $45 \mathrm{~S} 5 \mathrm{BG}$ first show semi-crystallization peaks at $2 \theta=26^{\circ}$ and $2 \theta=32^{\circ}$ after 7 days of immersion, whereas the films containing non-doped 45S5 BG already show such peaks at day 3 . The crystalline structure of the new phase depicted by XRD peaks seems to match that of hydroxyapatite crystals (JCPDS file number 9-432). In general, the relative 
intensity of peaks corresponding to hydroxyapatite formation in all coatings increases with increasing immersion time in SBF.

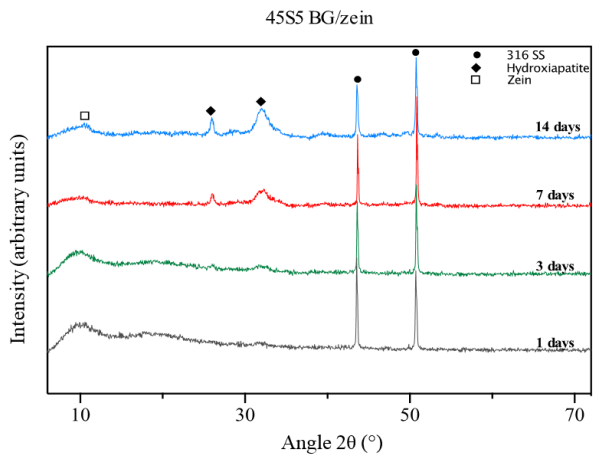

(a)

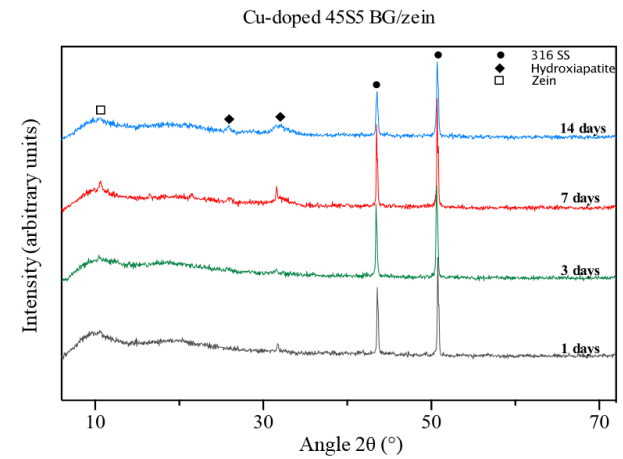

(b)

Figure 4. XRD results on coatings soaked in SBF for different immersion times, from 1 to 14 days:

(a) 45S5 BG/zein coatings; (b) copper-doped 45S5 BG/zein coatings.

\subsection{SEM Observation}

In order to evaluate the coating homogeneity, uniformity, and surface morphology, SEM micrographs were obtained and are shown in Figure 5 at two magnifications. The surfaces of both coatings look fairly homogeneous with BG particles spreading across the surface of the zein film. During imaging in conventional ultra high vacuum (UHV) SEM mode, coating cracking was observed: environmental SEM was subsequently used for further investigations.

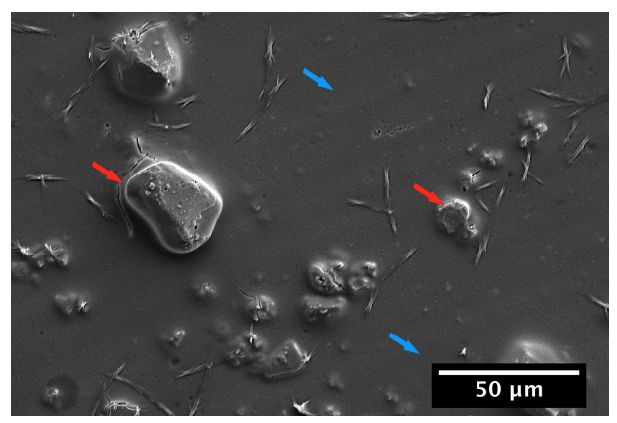

(a)

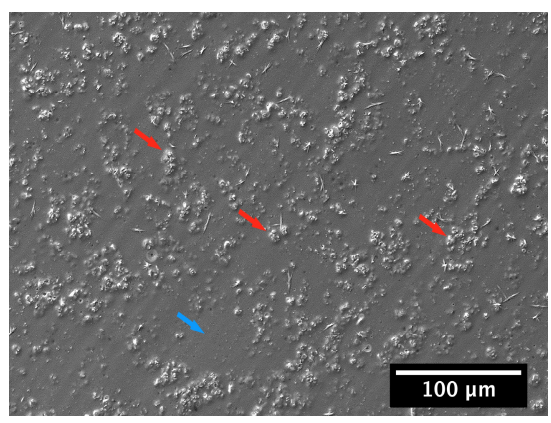

(b)

Figure 5. SEM images showing the microstructure of EPD films produced with (a) Cu-doped $45 \mathrm{~S} 5 \mathrm{BG} /$ zein and (b) $45 \mathrm{~S} 5 \mathrm{BG}$ / zein at two magnifications, showing BG particles (red arrow) embedded in zein (blue arrow) on the surface of the coatings.

\subsection{ESEM Observation}

Figure 6 shows micrographs of the surface of the produced EPD films. The images show coatings immersed in SBF for 1 day (Figure 6a,b) and 14 days (Figure 6c,d). The ESEM images of the films obtained at shorter immersion times reveal a porous structure with an abundance of zein covering the surface. The zein molecules interact with the aqueous mixture of SBF. The degradation of zein seems to have started after just 1 day of immersion in SBF as some pores on the surface of the coatings have already been formed. Continuing to the maximum time of immersion, almost all zein surface layers had degraded leading to the formation of a porous structure covering the stainless steel substrate. Moreover, the bright areas on the surface of the coatings, especially on those immersed for 14 days in SBF, could be an indication of the formation of hydroxyapatite as confirmed by FTIR and XRD.

The surface morphology of the coatings produced with Cu-doped 45S5 BG immersed in SBF is shown in Figure 7. These micrographs show evidence of zein degradation on day 1 following 
immersion in SBF, leading to the appearance of holes on the surface of the films (Figure 7a,b). After 14 days of soaking, the Cu-doped 45S5 BG/zein coating exhibits further degradation whilst maintaining sufficient material to cover the steel substrate (Figure 7c,d), in contrast to that of the $\mathrm{Cu}$-free BG system. Moreover, the small number of bioactive glass particles observed on both types of coatings indicates that some particles may have been released in the SBF solution after degradation of zein or have dissolved to form HA.

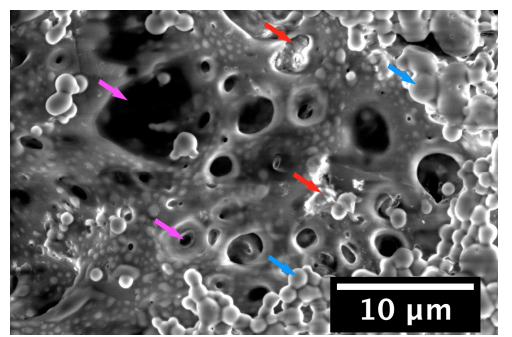

(a)

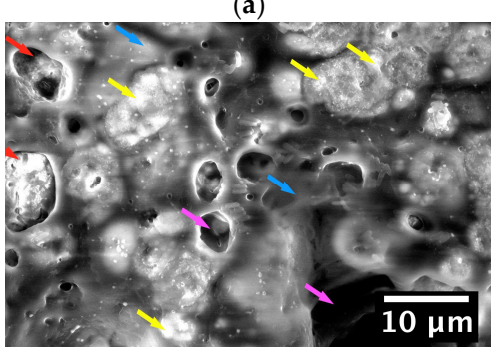

(c)

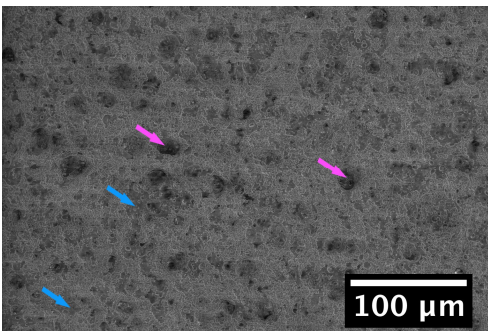

(b)

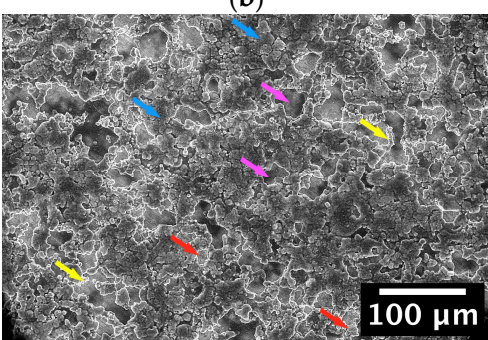

(d)

Figure 6. Environmental SEM (ESEM) images showing the microstructure of $45 \mathrm{~S} 5 \mathrm{BG} /$ zein coating surfaces produced by EPD and immersed in SBF for: $(\mathbf{a}, \mathbf{b}) 1$ day and $(\mathbf{c}, \mathbf{d}) 14$ days. BG particles (red arrow) are embedded in zein (blue arrow) which undergoes a degradation process (magenta arrow) indicated by the holes that appear on the coating surface. Formation of hydroxyapatite (HA) (yellow arrow) is visible on some of the coatings.

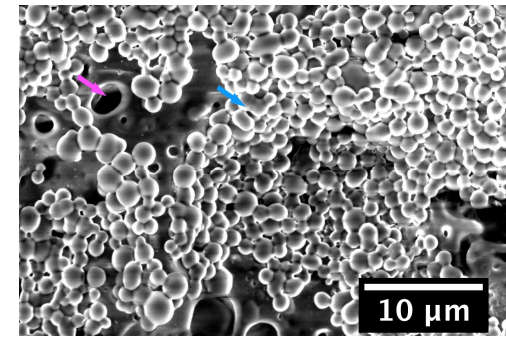

(a)

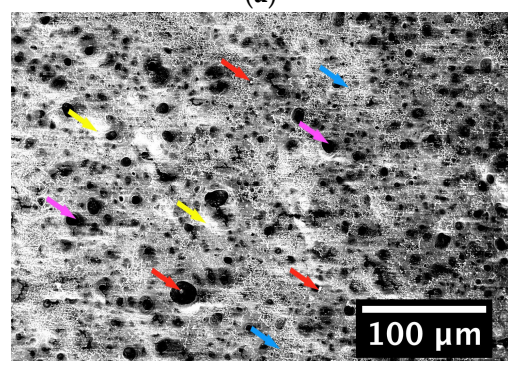

(c)

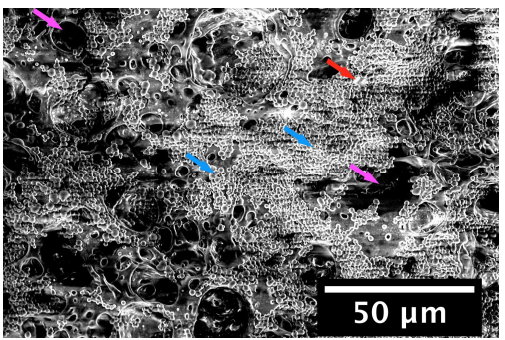

(b)

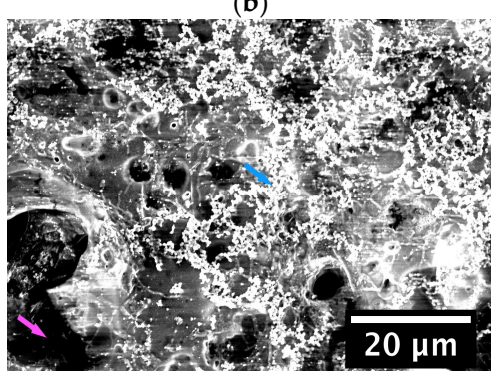

(d)

Figure 7. ESEM images showing the morphology of Cu-doped 45S5 BG/zein coating surfaces produced by EPD and immersed in SBF for: $(\mathbf{a}, \mathbf{b}) 1$ day and $(\mathbf{c}, \mathbf{d}) 14$ days. BG particles (red arrow) are embedded in zein (blue arrow) which undergoes degradation (magenta arrow) visualized by holes that appear on the coating surface. Formation of hydroxyapatite (yellow arrow) is visible on some of the coatings. 


\subsection{EDS Results}

In order to determine the elemental composition of the samples, EDS was utilized to compare coatings containing both forms of bioactive glass, in particular with respect to the elemental confirmation of hydroxyapatite formation, a key marker of coating bioactivity. EDS was only performed on coatings that had been immersed for 14 days in SBF.

Figure 8 shows the elemental composition of $45 \mathrm{~S} 5 \mathrm{BG} /$ zein films after 14 days of soaking in SBF. The EDS spectrum shows a $\mathrm{Ca} / \mathrm{P}$ ratio of 2.29 which could be attributed to the presence of unreacted $\mathrm{BG}$ particles in the selected area while for pure $\mathrm{HA}$ the $\mathrm{Ca} / \mathrm{P}$ ratio is 1.67 . The fact that the mass percentage of silicon is low when compared to that of phosphorus and calcium (characteristic elements of bioactive glass), suggests the formation of hydroxyapatite. Additionally, the residual presence of zein after a 14-day immersion period was supported by a high mass percentage of carbon. Figure 9 shows the EDS spectrum of the $\mathrm{Cu}$-doped $45 \mathrm{~S} 5 \mathrm{BG} /$ zein coatings. The $\mathrm{Ca} / \mathrm{P}$ ratio of almost 2.0 suggests the formation of hydroxyapatite and the relatively high mass percentage of carbon (27.81\%) indicates the presence of zein within the surveyed region. In general, the results of EDS are in line with the previous results obtained through XRD and FTIR. The presence of zein was confirmed in all samples, although the degradation of this polymer in Cu-doped BG based coatings was less pronounced, which is presumably due to binding forces between copper and zein molecules during the EPD process that retard the degradation steps during immersion in SBF.

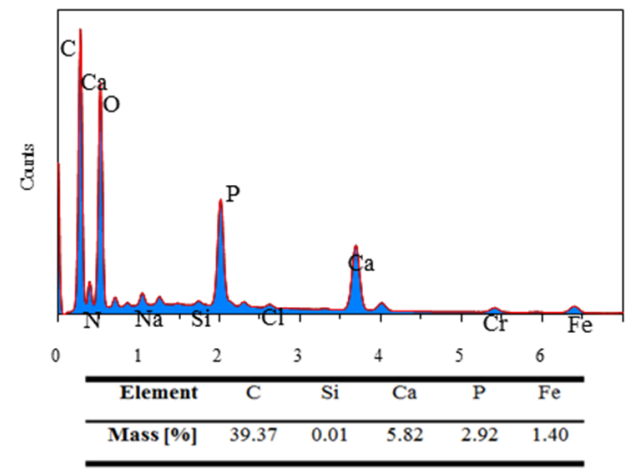

(a)

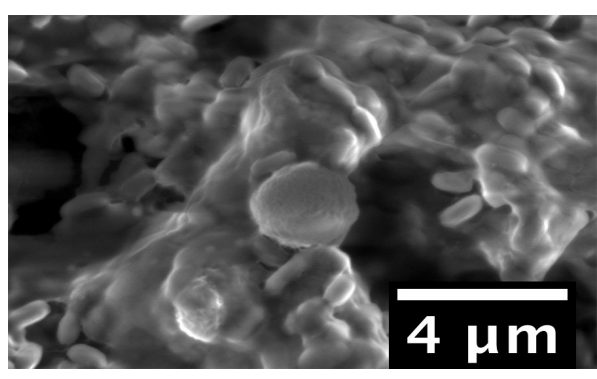

(b)

Figure 8. Energy dispersive spectroscopy (EDS)-spectrum (a) and the corresponding ESEM image (b) of a selected area of $45 \mathrm{~S} 5 \mathrm{BG} /$ zein coating surface.

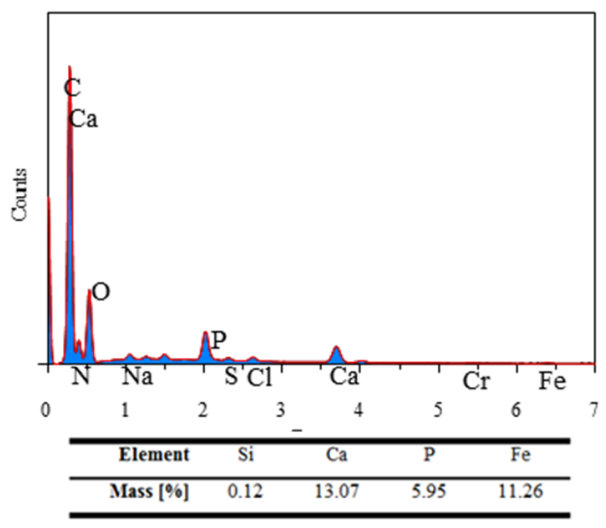

(a)

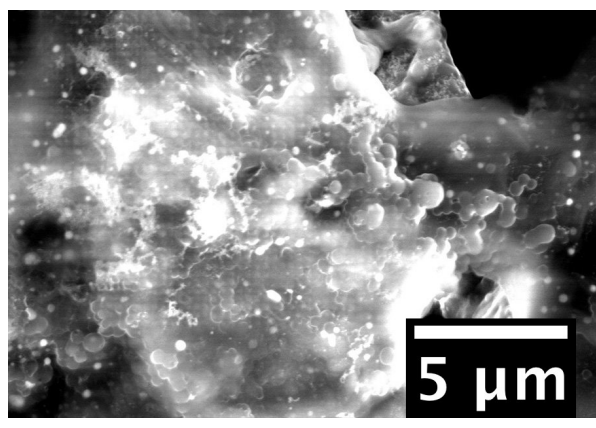

(b)

Figure 9. EDS-spectrum (a) and the corresponding ESEM image (b) of a selected area of Cu-doped $45 \mathrm{~S} 5 \mathrm{BG} /$ zein coating surface. 


\section{Discussion}

Orthopedic implants are used to restore the skeletal structure after fractures or abnormal growth of bone. Most orthopedic implants are made of metallic alloys that are in general not ideal for this application because of possible release of metallic ions in the human body and encapsulation by fibrous tissue. Electrophoretic deposition of organic/inorganic composites on metallic alloys is being considered in order to modify the surface of metallic implants, both stainless steel and titanium alloys $[6,8,10,12]$. These composite coatings can induce osseointegration with host tissue and enhance the bulk and surface properties of the implants. For this approach, EPD has been used successfully to manufacture coatings of a variety of compositions $[6,8,10,12,25,33]$.

In this study, after an optimization step of the EPD process using different zein/BG concentrations, voltage, and time of deposition, coatings exhibiting a homogeneous surface without cracks were produced (Figure 2a,b). Comparing the produced coatings with other coatings reported in the literature [6], it seems that they present low BG concentration, possibly because of lower mobility of BG particles in contact with zein molecules during the deposition process. The weak suspension stability (low $\zeta$ potential values) leads to deposition on both electrodes (anodic and cathodic) because of the characteristics of the zein structure, as discussed above.

Formation of HA was observed on the coatings with a relatively high amount of BG, which means that increasing the amount of bioactive glass will enhance the ability of the coating to bond to bone. However, films with $8 \mathrm{wt}$.\% BG concentration were able to build hydroxyapatite after 3 days of immersion in SBF. According to the results of the TGA measurements, a higher content of BG reduces the content of zein resulting in less polymer to be degraded. The polymer degradation can thus be controlled by the relation between the bioactive glass particles and biopolymer content; in this way, achieving relatively fast or slow dissolution of BG particles in the medium is possible.

\section{Conclusions}

We have shown the effective electrophoretic deposition of organic/inorganic composites on stainless steel, forming two coatings of zein containing 45S5 BG and Cu-doped 45S5 BG fillers. The coatings showed homogeneous and near crack-free surfaces with BG particles distributed in the entire film. In terms of bioactive behavior, the results demonstrated hydroxyapatite formation in all composite coatings after seven days of immersion in SBF. FTIR results not only indicated the hydroxyapatite formation on the coatings, which was in line with the XRD and ESEM results, but also confirmed the existence of zein and BG particles. FTIR results showed that upon increasing the SBF immersion time, the degradation process of zein in coatings containing 45S5 BG increased. Coatings produced with $\mathrm{Cu}$-doped $45 \mathrm{~S} 5 \mathrm{BG}$ appeared to slow down the degradation process of zein, likely due to the cross-linking effect of released $\mathrm{Cu}$ ions. The results confirm EPD as a convenient technique to fabricate BG-zein composite coatings of suitable bioactivity which can be considered for orthopedic applications.

Acknowledgments: We would like to thank Eleonora Calì (IC) for technical support, Alexandra Porter (IC) for useful discussions and suggestions, the Shell-Imperial Center for Advanced Interfacial Materials Science for access to ESEM, and the European Commission for financial support in the framework of the Erasmus + program. Laura Ramos Rivera thanks the German Academic Exchange Service (DAAD) for a fellowship and COLCIENCIAS for financial support.

Author Contributions: Laura Ramos Rivera and Aldo R. Boccaccini conceived and designed the experiments; Nima Meyer, Laura Ramos Rivera, Tim Ellis and Jiahui Qi performed the experiments; all authors analyzed and discussed the data; Aldo R. Boccaccini and Mary P. Ryan contributed reagents, materials and analysis tools; Nima Meyer wrote the first draft of the paper. All authors contributed to the writing and elaboration of the paper, including corrections. Aldo R. Boccaccini supervised the complete research.

Conflicts of Interest: The authors declare no conflict of interest. 


\section{References}

1. Kitsugi, T.; Nakamura, T.; Oka, M.; Senaha, Y.; Goto, T.; Shibuya, T. Bone-bonding behavior of plasma-sprayed coatings of BioglassR, AW-glass ceramic, and tricalcium phosphate on titanium alloy. J. Biomed. Mater. Res. 1996, 30, 261-269. [CrossRef]

2. Albrektsson, T.; Brånemark, P.-I.; Hansson, H.-A.; Lindström, J. Osseointegrated titanium implants: Requirements for ensuring a long-lasting, direct bone-to-implant anchorage in man. Acta Orthop. Scand. 1981, 52, 155-170. [CrossRef] [PubMed]

3. Duan, K.; Wang, R. Surface modifications of bone implants through wet chemistry. J. Mater. Chem. 2006, 16, 2309-2321. [CrossRef]

4. Boccaccini, A.R.; Peters, C.; Roether, J.A.; Eifler, D.; Misra, S.K.; Minay, E.J. Electrophoretic deposition of polyetheretherketone (PEEK) and PEEK/Bioglass coatings on NiTi shape memory alloy wires. J. Mater. Sci. 2006, 41, 8152-8159. [CrossRef]

5. Zhao, Y.; Song, M.; Liu, J. Characteristics of bioactive glass coatings obtained by pulsed laser deposition. Surf. Interface Anal. 2008, 40, 1463-1468. [CrossRef]

6. Cordero-Arias, L.; Cabanas-Polo, S.; Goudouri, O.M.; Misra, S.K.; Gilabert, J.; Valsami-Jones, E.; Sanchez, E.; Virtanen, S.; Boccaccini, A.R. Electrophoretic deposition of $\mathrm{ZnO} /$ alginate and $\mathrm{ZnO}$-bioactive glass/alginate composite coatings for antimicrobial applications. Mater. Sci. Eng. C 2015, 55, 137-144. [CrossRef] [PubMed]

7. Oliva, A.; Salerno, A.; Locardi, B.; Riccio, V.; Della Ragione, F.; Iardino, P.; Zappia, V. Behaviour of human osteoblasts cultured on bioactive glass coatings. Biomaterials 1998, 19, 1019-1025. [CrossRef]

8. Zhitomirsky, D.; Roether, J.A.; Boccaccini, A.R.; Zhitomirsky, I. Electrophoretic deposition of bioactive glass/polymer composite coatings with and without HA nanoparticle inclusions for biomedical applications. J. Mater. Process. Technol. 2009, 209, 1853-1860. [CrossRef]

9. Hahn, B.-D.; Park, D.-S.; Choi, J.-J.; Ryu, J.; Yoon, W.-H.; Choi, J.-H.; Kim, H.-E.; Kim, S.-G. Aerosol deposition of hydroxyapatite-chitosan composite coatings on biodegradable magnesium alloy. Surf. Coat. Technol. 2011, 205, 3112-3118. [CrossRef]

10. Clavijo, S.; Membrives, F.; Quiroga, G.; Boccaccini, A.R.; Santillán, M.J. Electrophoretic deposition of chitosan/Bioglass ${ }^{\circledR}$ and chitosan/Bioglass ${ }^{\circledR} / \mathrm{TiO}_{2}$ composite coatings for bioimplants. Ceram. Int. 2016, 42, 14206-14213. [CrossRef]

11. Lyndon, J.A.; Boyd, B.J.; Birbilis, N. Metallic implant drug/device combinations for controlled drug release in orthopaedic applications. J. Control. Release 2014, 179, 63-75. [CrossRef] [PubMed]

12. Pang, X.; Zhitomirsky, I. Electrophoretic deposition of composite hydroxyapatite-chitosan coatings. Mater. Charact. 2007, 58, 339-348. [CrossRef]

13. Malafaya, P.B.; Silva, G.A.; Reis, R.L. Natural-origin polymers as carriers and scaffolds for biomolecules and cell delivery in tissue engineering applications. Adv. Drug Deliv. Rev. 2007, 59, 207-233. [CrossRef] [PubMed]

14. Fu, J.-X.; Wang, H.-J.; Zhou, Y.-Q.; Wang, J.-Y. Antibacterial activity of ciprofloxacin-loaded zein microsphere films. Mater. Sci. Eng. C 2009, 29, 1161-1166. [CrossRef]

15. Han, Y.-L.; Xu, Q.; Lu, Z.; Wang, J.-Y. Cell adhesion on zein films under shear stress field. Colloids Surf. B 2013, 111, 479-485. [CrossRef] [PubMed]

16. Shukla, R.; Cheryan, M. Zein: The industrial protein from corn. Ind. Crops Prod. 2001, 13, 171-192. [CrossRef]

17. Esen, A. A proposed nomenclature for the alcohol-soluble proteins (zeins) of maize (Zea mays L.). J. Cereal Sci. 1987, 5, 117-128. [CrossRef]

18. Lawton, J.W. Zein: A history of processing and use. Cereal Chem. 2002, 79, 1-18. [CrossRef]

19. Corradini, E.; Curti, P.; Meniqueti, A.; Martins, A.; Rubira, A.; Muniz, E. Recent advances in food-packing, pharmaceutical and biomedical applications of zein and zein-based materials. Int. J. Mol. Sci. 2014, 15, 22438-22470. [CrossRef] [PubMed]

20. Zhang, Y.; Cui, L.; Che, X.; Zhang, H.; Shi, N.; Li, C.; Chen, Y.; Kong, W. Zein-based films and their usage for controlled delivery: Origin, classes and current landscape. J. Control. Release 2015, 206, 206-219. [CrossRef] [PubMed]

21. Demir, M.; Ramos-Rivera, L.; Silva, R.; Nazhat, S.N.; Boccaccini, A.R. Zein-based composites in biomedical applications. J. Biomed. Mater. Res. Part A 2017, 105, 1656-1665. [CrossRef] [PubMed]

22. Peña, J.; Izquierdo-Barba, I.; García, M.; Vallet-Regí, M. Room temperature synthesis of chitosan/apatite powders and coatings. J. Eur. Ceram. Soc. 2006, 26, 3631-3638. [CrossRef] 
23. Yuan, W.; Ji, J.; Fu, J.; Shen, J. A facile method to construct hybrid multilayered films as a strong and multifunctional antibacterial coating. J. Biomed. Mater. Res. Part B 2008, 85B, 556-563. [CrossRef] [PubMed]

24. Costa, R.R.; Mano, J.F. Layer-by-layer self-assembly techniques for nanostructured devices in tissue engineering. In Nanomaterials in Tissue Engineering: Fabrication and Applications; Gaharwar, A.K., Sant, S., Hancock, M.J., Hacking, S.A., Eds.; Woodhead Publishing Limited: Cambridge, UK, 2013.

25. Boccaccini, A.R.; Keim, S.; Ma, R.; Li, Y.; Zhitomirsky, I. Electrophoretic deposition of biomaterials. J. R. Soc. Interface 2010, 7, S581-S613. [CrossRef] [PubMed]

26. Besra, L.; Liu, M. A review on fundamentals and applications of electrophoretic deposition (EPD). Prog. Mater. Sci. 2007, 52, 1-61. [CrossRef]

27. Kaya, S.; Boccaccini, A.R. Electrophoretic deposition of zein coatings. J. Coat. Technol. Res. 2017, 14, 683-689. [CrossRef]

28. Chen, Y.; Ye, R.; Xu, H. Physicochemical properties of zein-based films by electrophoretic deposition using indium tin oxide electrodes: Vertical and horizontal electric fields. Int. J. Food Prop. 2016, 19, $945-957$. [CrossRef]

29. Chen, Y.; Ye, R.; Wang, J. Effect of voltage on the mechanical and water resistance properties of zein films by electrophoretic deposition. Food Bioprocess Technol. 2015, 8, 486-491. [CrossRef]

30. Hoppe, A.; Meszaros, R.; Stähli, C.; Romeis, S.; Schmidt, J.; Peukert, W.; Marelli, B.; Nazhat, S.N.; Wondraczek, L.; Lao, J.; et al. In vitro reactivity of $\mathrm{Cu}$ doped $45 \mathrm{~S} 5$ Bioglass ${ }^{\circledR}$ derived scaffolds for bone tissue engineering. J. Mater. Chem. B 2013, 1, 5659-5674. [CrossRef]

31. Kokubo, T.; Takadama, H. How useful is SBF in predicting in vivo bone bioactivity? Biomaterials 2006, 27, 2907-2915. [CrossRef] [PubMed]

32. Li, Y.; Li, J.; Xia, Q.; Zhang, B.; Wang, Q.; Huang, Q. Understanding the dissolution of $\alpha$-zein in aqueous ethanol and acetic acid solutions. J. Phys. Chem. B 2012, 116, 12057-12064. [CrossRef] [PubMed]

33. Zhitomirsky, I.; Hashambhoy, A. Chitosan-mediated electrosynthesis of organic-inorganic nanocomposites. J. Mater. Process. Technol. 2007, 191, 68-72. [CrossRef]

34. Li, P.; Zhang, F. The electrochemistry of a glass surface and its application to bioactive glass in solution. J. Non. Cryst. Solids 1990, 119, 112-118. [CrossRef]

35. Lide, D.R. CRC Handbook of Chemistry and Physics, 84th ed.; CRC Press: Boca Raton, FL, USA, 2003; p. 2616. [CrossRef]

36. Dhandayuthapani, B.; Varghese, S.H.; Aswathy, R.G.; Yoshida, Y.; Maekawa, T.; Sakthikumar, D. Evaluation of antithrombogenicity and hydrophilicity on zein-SWCNT electrospun fibrous nanocomposite scaffolds. Int. J. Biomater. 2012, 2012, 345029. [CrossRef] [PubMed]

37. Sessa, D.J.; Mohamed, A.; Byars, J.A. Chemistry and physical properties of melt-processed and solution-cross-linked corn zein. J. Agric. Food Chem. 2008, 56, 7067-7075. [CrossRef] [PubMed]

38. Boccaccini, A.R.; Chen, Q. Sintering, crystallisation and biodegradation behaviour of Bioglass ${ }^{\circledR}$-derived glass-ceramics. Faraday Discuss. 2007, 136, 27-44. [CrossRef] [PubMed]

39. Zhou, P.; Xia, Y.; Wang, J.; Liang, C.; Yu, L.; Tang, W.; Gu, S.; Xu, S. Antibacterial properties and bioactivity of HACC- and HACC-Zein-modified mesoporous bioactive glass scaffolds. J. Mater. Chem. B 2013, 1, 685-692. [CrossRef]

40. Filho, O.P.; LaTorre, G.P.; Hench, L.L. Effect of crystallization on apatite-layer formation of bioactive glass 45S5. J. Biomed. Mater. Res. 1996, 30, 509-514. [CrossRef]

41. Tian, Z.; Pawlow, A.; Poutsma, J.C.; Kass, S.R. Are carboxyl groups the most acidic sites in amino acids? Gas-phase acidity, H/D exchange experiments, and computations on cysteine and its conjugate base. J. Am. Chem. Soc. 2007, 129, 5403-5407. [CrossRef] [PubMed]

42. Wu, Z.; Fernandez-Lima, F.A.; Russell, D.H. Amino acid influence on copper binding to peptides: Cysteine versus arginine. J. Am. Soc. Mass Spectrom. 2010, 21, 522-533. [CrossRef] [PubMed]

43. Patel, A.; Hu, Y.; Tiwari, J.K.; Velikov, K.P. Synthesis and characterisation of zein-curcumin colloidal particles. Soft Matter. 2010, 6, 6192-6199. [CrossRef]

(C) 2018 by the authors. Licensee MDPI, Basel, Switzerland. This article is an open access article distributed under the terms and conditions of the Creative Commons Attribution (CC BY) license (http:/ / creativecommons.org/licenses/by/4.0/). 